\title{
Research on Construction Risk Control of International Project
}

\author{
Lixiang $\mathrm{Cao}^{{ }^{*}}$ \\ ${ }^{1}$ College of Civil Engineering, Longdong University, Qingyang, Gansu, 745000, China
}

\begin{abstract}
From the perspective of China's construction enterprises, taking the nature of risk and engineering's characteristics into account. The paper apply the Delphi Method to establish primeval list of international project construction risk, use Analytic Hierarchy Process to conduct a comprehensive evaluation to risk factors in the primeval list of international project construction risk, identify risk factors and put forward coping strategies, The ultimate goal is to provide reference and a basis for risk management of construction companies involved in international project construction.
\end{abstract}

\section{Introduction}

With the deepening of economic globalization, the scale of international project market is expanding rapidly, and the market opportunities are increasing constantly. However, due to the decrease of capital availability rate, difficulties in contract negotiation, unoptimistic overseas security, and the aggravation of trade protectionism, Chinese construction enterprises face greater risks in the construction of international projects [1-3]. Therefore, to improve the awareness of risk management, enhance the ability of risk identification, and establish an effective risk management mechanism are very important for Chinese construction enterprises to go abroad and enter the international market.
International engineering projects are characterized by long construction period, complex engineering environment, numerous contractor and transnational economic activities, etc., and there are many risk factors affecting the construction of international projects. In this paper, the risk factors affecting the construction of international projects are divided into external risks and internal risks according to different risk sources. External risks include economic risks, political risks, natural environmental risks, social and cultural risks, etc., which are not controlled by project managers [4-5]. Internal risks include owner's risk, contractor's risk, material supplier's risk, etc. By consulting relevant literature and FIDIC contract terms, we found out the common risk factors in the construction of international projects, as shown in Table 1.

\section{Classification of risk factors}

Table 1. Common risk factors in the construction stage of International projects.

\begin{tabular}{lll}
\hline Risk sources & Risk category & Risk factor \\
\hline External risk & Political risk & Integrity of the government \\
& & State external relations \\
& Credibility of the government \\
& Relationship between host country and China \\
& Political situation \\
& Policy situation \\
& Nationalization risk \\
& Local protectionism \\
& Changes in labour and materials markets \\
& Inflation risk \\
& Foreign exchange risk \\
& Financial risk \\
\hline
\end{tabular}

*Corresponding author's e-mail: 56288028@qq.com 


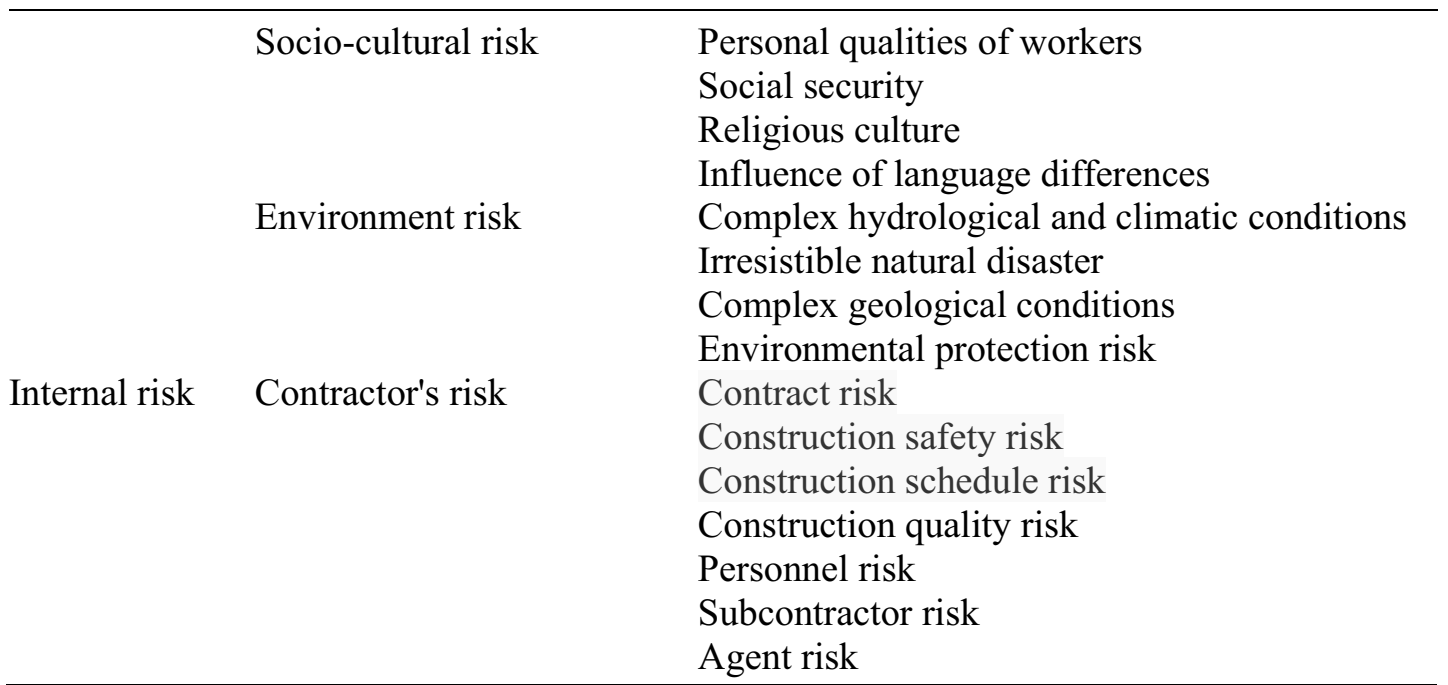

\section{Risk identification}

Risk identification is the basis of risk quantification and evaluation, which plays a very important role in the process of risk management. The methods we usually use are: Checklist method, Scenario Analysis, Delphi method, Flow Chart method, Brainstorming, SWOT Analysis, sensitivity analysis and WBS.

In this paper, Delphi method is used to identify the risks in the construction stage of international projects. Delphi method has two ways: one is to call relevant experts to attend the meeting, the other is to use questionnaire survey. In this study, a questionnaire survey method was adopted to select experts with certain authority in the field of international project research and practice, mainly including university researchers, trade association workers, experts from large construction enterprises or construction project consulting institutions. There are 9 interviewees, of which 6 have more than 5 years of project management theoretical research or practical experience as well as more than 3 years of international project theoretical research or practical experience. The average age of the interviewees is 45.5 years old.

Through data analysis and Delphi method, we summarize the opinions and suggestions of experts, remove the less important risk factors in the questionnaire and revise some risk factors to make the primeval list of international project construction risk, As shown in Table 2.

Table 2. Primeval list of construction risks of international projects

\begin{tabular}{lll}
\hline Risk sources & Risk category & Risk factor \\
\hline External risk & Political risk & Integrity of the government \\
& & Credibility of the government \\
& Relationship between host country and China \\
& & Political situation \\
& & Policy situation \\
& & Local protectionism \\
& Economical risk & Changes in labour and materials markets \\
& & Inflation risk \\
& & Foreign exchange risk \\
& Socio-cultural risk & Interest Rate risk \\
& & Personal qualities of workers \\
& Environment risk & Religious culture \\
& & Complex hydrological and climatic conditions \\
& & Irresistible natural disaster \\
& & Complex geological conditions \\
Internal risk & Convironmental protection risk \\
& & Management risk \\
& & Technical risk \\
& & Financial risk \\
& & Personnel risk \\
\hline
\end{tabular}




\section{Risk analysis}

\subsection{Project risk analysis overview}

Risk analysis is not only the basis of risk response, but also the basis of project decision. The risk analysis of engineering project is generally divided into three steps, as shown in Figure 1 [4].

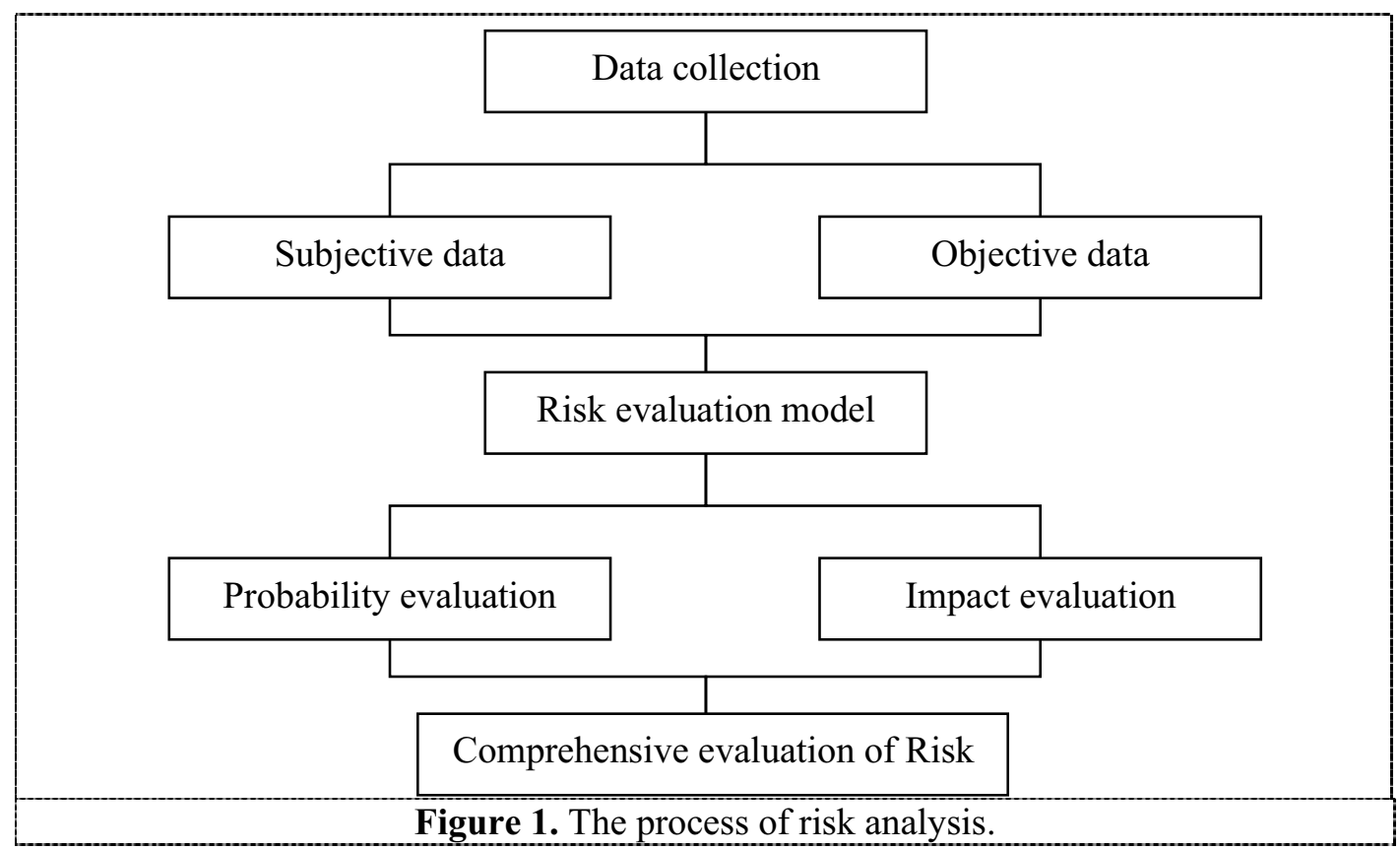

\subsubsection{Collecting data.}

Data collection is the basis of risk analysis. The collected data can be divided into subjective data and objective data. These data can be obtained from various professional databases through the Internet, and also from the data of similar projects of contractors or owners. When collecting data, we must adhere to the principles of objectivity, timeliness and statistics.

\subsubsection{Construct evaluation model.}

In order to effectively apply the collected data, it is necessary to construct a risk assessment model with the help of certain mathematical methods to quantify the possibility of risk occurrence and possible consequences. Generally speaking, the probability is used to represent the occurrence of the risk, and the economic loss is used to reflect consequences of the risk.

\subsubsection{Comprehensive evaluation of risk impact.}

After quantifying the risk factors, comprehensively evaluate the impact of these risks.

\subsection{Main methods of project risk analysis}

Nowadays, there are many methods that can be used in risk assessment and evaluation, which can be divided into three categories: (1) qualitative analysis, mainly including questionnaire and expert scoring method; (2) quantitative analysis, mainly including fuzzy mathematics, sensitivity analysis and probability method; (3) methods combining qualitative and quantitative, mainly including analytic hierarchy process, Monte Carlo simulation. This paper mainly uses AHP to estimate and evaluate the risk.

First, clarify the types and logical relationships of risk factors, and apply the work breakdown structure method to analyze the hierarchical structure of risk factors. As shown in Figure 2. 


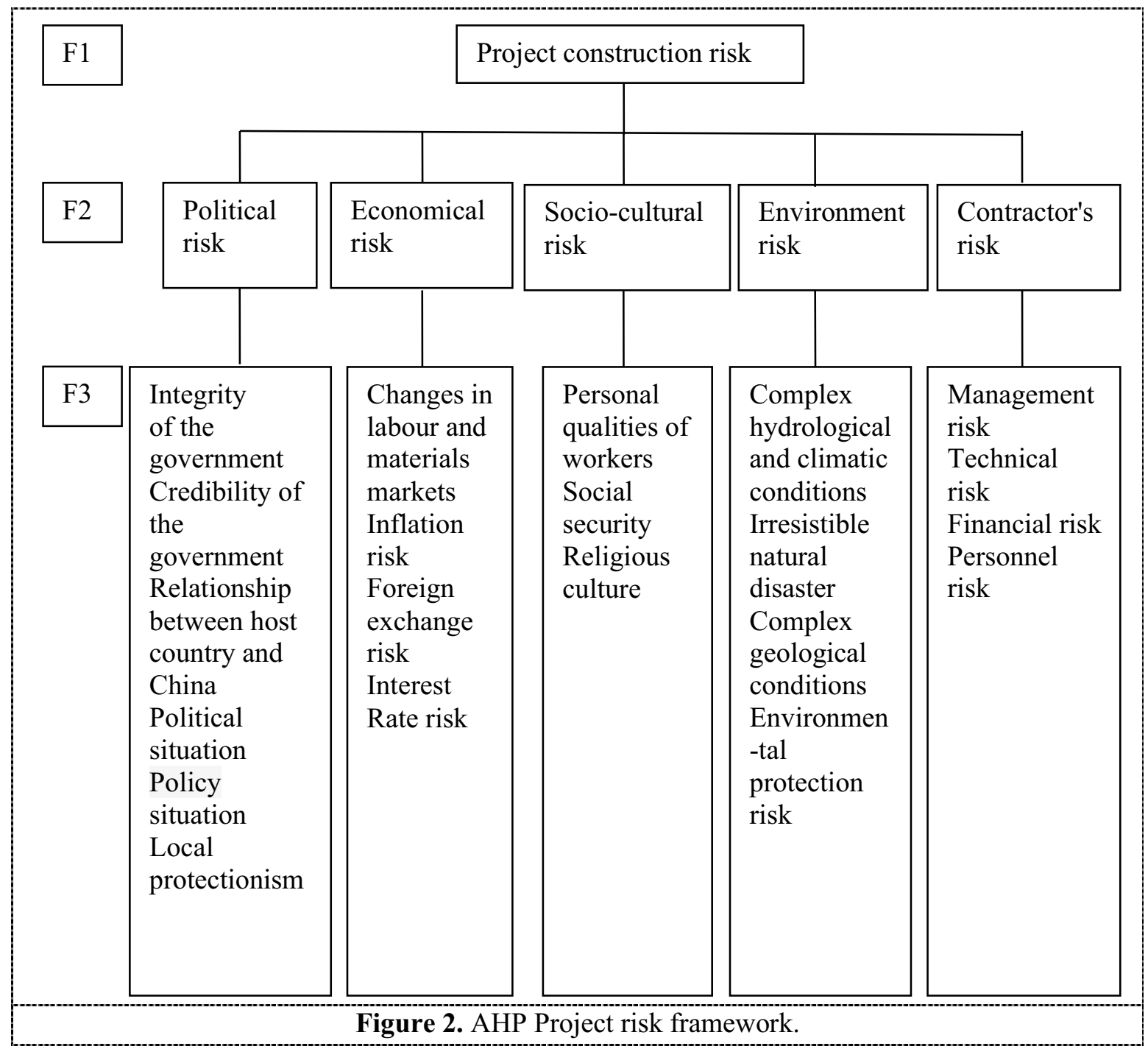

According to the figure 2, we use expert scoring first level sub-project according to the importance degree, method to give weight value to each risk factor of the and construct the judgement matrix. As shown in Table 3.

Table 3. Risk factor judgment matrix.

\begin{tabular}{lccccc}
\hline Index & $\begin{array}{c}\text { Political risk Economical } \\
\text { risk }\end{array}$ & $\begin{array}{l}\text { Socio-cultural } \\
\text { risk }\end{array}$ & $\begin{array}{l}\text { Environment } \\
\text { risk }\end{array}$ & $\begin{array}{l}\text { Contractor's } \\
\text { risk }\end{array}$ \\
\hline Political risk & 1 & 3 & 4 & 4 & 5 \\
Economical risk & $1 / 3$ & 1 & 4 & 4 & 5 \\
Socio-cultural risk & $1 / 4$ & $1 / 4$ & 1 & $1 / 2$ & 3 \\
Environment risk & $1 / 4$ & $1 / 4$ & 2 & 1 & 3 \\
Contractor's risk & $1 / 5$ & $1 / 5$ & $1 / 3$ & $1 / 3$ & 1 \\
\hline
\end{tabular}

So, the judgment matrix is

$$
R=\left(\begin{array}{ccccc}
1 & 3 & 4 & 4 & 5 \\
1 / 3 & 1 & 4 & 4 & 5 \\
1 / 4 & 1 / 4 & 1 & 1 / 2 & 3 \\
1 / 4 & 1 / 4 & 2 & 1 & 3 \\
1 / 5 & 1 / 5 & 1 / 3 & 1 / 3 & 1
\end{array}\right)
$$

Analysis the judgment matrix with AHP method

The first, calculation of $\mathrm{N}_{\mathrm{i}}$ 


$$
N_{i}=\prod_{j=1}^{n} b_{i j}, \mathrm{i}=1,2, \ldots \ldots, \mathrm{n}
$$

In the formula: $b_{i j}$ is the element in row I and column $\mathrm{J}$

$\mathrm{N}_{1}=240, \mathrm{~N}_{2}=26.6667, \mathrm{~N}_{3}=0.0938, \mathrm{~N}_{2}=0.3750, \mathrm{~N}_{2}$ $=0.0044$

The Second, calculation of $\overline{w_{i}}$

$\overline{w_{i}}=\sqrt[n]{N_{i}}, \mathrm{i}=1,2,3, \ldots \ldots, \mathrm{n}$

$\bar{w}_{1}=2.9926, \bar{w}_{2}=1.9283, \bar{w}_{3}=0.6229, \bar{w}_{4}=0.8219$, $\bar{w}_{5}=0.3378$

The Third, Normalize $\left(\begin{array}{llllll}\bar{w}_{1} & \bar{w}_{2} & \bar{w}_{3} & \bar{w}_{4} & \bar{w}_{5}\end{array}\right)^{\mathrm{T}}$ to find each eigenvector $w_{i}$

$$
w_{i}=\frac{\overline{w_{i}}}{\sum_{i=1}^{n} \overline{w_{i}}}
$$

$w_{i}$ is the weight value of each factor

$$
w_{1}=0.4464, w_{2}=0.2877, w_{3}=0.0929, w_{4}=0.1226 \text {, }
$$

$w_{5}=0.0504$

The fourth, consistency test. Calculation of $\mathrm{A}_{\mathrm{Ni}}$, $\lambda_{\text {max }}$ and CI.

$\mathrm{A}_{\mathrm{N} 1}=2.4235, \mathrm{~A}_{\mathrm{N} 2}=1.5505 ; \quad \mathrm{A}_{\mathrm{N} 3}=0.4889 ;$

$\mathrm{A}_{\mathrm{N} 4}=0.6431 ; \mathrm{A}_{\mathrm{N} 5}=0.2691$,

$$
\lambda_{\text {max }}=\sum_{\mathrm{i}=1}^{5} \frac{\mathrm{A}_{\mathrm{Ni}}}{5 \times \mathrm{Ni}}=5.3331, \mathrm{CI}=\frac{\lambda_{\max }-5}{5-1}=0.0833
$$

Table 4. Random consistency index

\begin{tabular}{cccccccccc}
\hline $\begin{array}{c}\text { Matrix } \\
\text { order }\end{array}$ & 1 & 2 & 3 & 4 & 5 & 6 & 7 & 8 & 9 \\
\hline RI & 0.00 & 0.00 & 0.48 & 0.91 & 1.12 & 1.26 & 1.37 & 1.42 & 1.46
\end{tabular}

$\mathrm{CI} / \mathrm{RI}=0.0833 / 1.12=0.074<0.1 \quad$ Similarly, construct the judgment matrix of each

It betrayed that the consistency of the judgment matrix has passed the test and can be accepted.

For the first level subproject of risk factors, according to the above analysis results, the risk weights of each factor can be obtained as $44.64 \%, 28.77 \%, 9.29 \%, 12.26 \%$ and $5.04 \%$ respectively. secondary sub-item of risk factors according to the above process, and obtain the weight value of each factor. Summarize the weight value of all risk factor into one table, as shown in Table 5.

Table 5. Risk factor weight value

\begin{tabular}{lllll}
\hline & Risk factor & $\begin{array}{c}\text { First } \\
\text { subproject }\end{array}$ & $\begin{array}{c}\text { Secondary } \\
\text { subproject }\end{array}$ & synthetic \\
\hline Political risk & Integrity of the government & 0.4464 & 0.1596 & 0.0712 \\
& $\begin{array}{l}\text { Credibility of the government } \\
\text { Relationship between host }\end{array}$ & 0.4464 & 0.1005 & 0.0449 \\
& $\begin{array}{l}\text { country and China } \\
\text { Political situation }\end{array}$ & 0.4464 & 0.0640 & 0.0286 \\
& Policy situation & 0.4464 & 0.3544 & 0.1582 \\
& Local protectionism & 0.4464 & 0.2813 & 0.1256 \\
Economical risk & Changes in labour and materials & 0.2877 & 0.3353 & 0.0179 \\
& markets & 0.2877 & 0.1295 & 0.0965 \\
& Inflation risk & 0.2877 & 0.4486 & 0.1291 \\
& Foreign exchange risk & 0.2877 & 0.0866 & 0.0249 \\
& Interest Rate risk & 0.0929 & 0.1060 & 0.0098 \\
Eocio-cultural risk & Personal qualities of workers & 0.0929 & 0.6335 & 0.0589 \\
& Social security & 0.0929 & 0.2604 & 0.0242 \\
& Religious culture & 0.1226 & 0.2532 & 0.0310 \\
& Complex hydrological and & & \\
& climatic conditions & 0.1226 & 0.1082 & 0.0133 \\
& Irresistible natural disaster & 0.1226 & 0.5731 & 0.0703 \\
& Complex geological conditions & 0.126 & 0.0080 \\
Contractor's risk & Environmental protection risk & 0.1226 & 0.0655 & 0.0100 \\
\hline
\end{tabular}




\begin{tabular}{llll}
\hline Technical risk & 0.0504 & 0.0848 & 0.0043 \\
Financial risk & 0.0504 & 0.6170 & 0.0311 \\
Personnel risk & 0.0504 & 0.0996 & 0.0050 \\
\hline
\end{tabular}

The risk factors in Table 5 are classified as follows:

The first category (risk weight value $w_{i} \geqslant 10 \%$ ): Political situation, Foreign exchange risk, Policy situation.

The second category (risk weight value $6 \% \leqslant w_{i}<$ $10 \%)$ : Changes in labour and materials markets, Integrity of the government, Complex geological conditions.

The third category (risk weight value $3 \% \leqslant w_{i}<6 \%$ ): Credibility of the government, Inflation risk, Complex hydrological and climatic conditions, Interest Rate risk, Social security.

The fourth category (risk weight value $w_{i}<3 \%$ ): the rest of factors

\section{Risk handling}

According to the results of risk identification, risk estimation and risk evaluation, the contractor must take special measures to control and deal with each risk factor.

According to the previous analysis, the main risk factors in the construction process of international projects are political situation risk, foreign exchange risk and policy situation. Now we propose specific measures for these major risk factors.

As for the political situation risk, local construction enterprises in China should keep close contacts with each other, learning more about the political situation of the country where the project is constructed through the overseas branches or production departments of each enterprise, and actively keep in touch with Chinese embassies and consulates abroad to get first-hand information as possible. In addition, some international consulting companies can also make predictions on the political situation in the country. In a word, all channels should be used to collect data to detect and make decisions as soon as possible for any major events that are not conducive to the project. Moreover, risks can be transferred by taking out political insurance. However, political insurance is only carried out in western countries, and there is no uniform standard for the cost, and it is very cumbersome to settle claims.

As for foreign exchange risk, the contractor may send special personnel or hire a consulting company to carefully study the economic situation of the country where the project is constructed, and carry out continuous monitoring of the economic situation of that country for a long time. In particular, always pay attention to the fluctuation range of its exchange rate and be alert to the occurrence of financial crisis, ensure the safety of funds; In addition, foreign exchange risks can also be transferred to foreign exchange Banks through some financial instruments, such as foreign exchange option transactions, selective transactions, remote foreign exchange transactions, swap transactions, and spot transactions. The contractor can also agree on the contract currency when signing the contract, such as using U.S. dollars to pay the contract price, in order to deal with losses caused by large exchange rate fluctuations;

As for the policy risk, the contractor can interpret the relevant documents by employing the personnel of the local legal institutions; for the possible controversial provisions, the Contractor shall actively communicate and confirm with the owner and the local government before signing the contract. If necessary, ask professionals to translate the documents into Chinese for all personnel involved in the project to learn and understand. It can also employ a full-time project management company to carry out collaborative management of the project.

\section{Conclusion}

According to the characteristics of international projects, this paper conducts a series of research and discussion on the risk factors in the construction phase of international projects, This paper uses Delphi method to identify the risks as well as uses the practical experience and theoretical knowledge of experts to intuitively judge the risks that China's Construction enterprises may encounter of the international projects. This paper establishes the primeval list of international project construction risk, evaluates the risk factors by using analytic hierarchy process, classifies the risk factors according to the severity, finds out the main risk factors and puts forward countermeasures, which provides reference and basis for the risk management of Chinese construction enterprises and has certain practical guiding significance.

\section{References}

1. Liu, Y.S. (2008) Construction Project Management. Beijing Institute of Technology Press, Bei jing.

2. MU, Y.Y.(2015) Risk Management of Construction Project Based on the Engineering Construction Contract of NEC. D. Hebei University of Engineering, Hebei.

3. Guo, H.F.(2019) Rearch on Analysis and Prevention of international engineering construction risk. J. Yunnan Science and Technology Management, 02: 58-60.

4. HE, T. (2003) Analysis and Research on construction risk of international engineering project. J. Construction Technology, 12: 26-28.

5. Ding, M.J.(2017) Rearch on Risk Management of General Construction Contractors in International Projects. D. Tianjin University. Tianjin.

6. Wang, J.D.(2006) Rearch on Risk Management of the Contractors in the International Construction 
Project. D. Dalian University of Technology, Dalian. 